\title{
YE YOUNG CHUNG, Malaise dans la morale bourgeoise: "Les Parents pauvres" de Balzac
}

\section{Marco Stupazzoni}

\section{OpenEdition}

\section{Journals}

\section{Edizione digitale}

URL: https://journals.openedition.org/studifrancesi/11858

DOI: 10.4000/studifrancesi. 11858

ISSN: 2421-5856

\section{Editore}

Rosenberg \& Sellier

\section{Edizione cartacea}

Data di pubblicazione: 1 avril 2018

Paginazione: 148-149

ISSN: 0039-2944

\section{Notizia bibliografica digitale}

Marco Stupazzoni, «Ye young chung, Malaise dans la morale bourgeoise: "Les Parents pauvres" de Balzac». Studi Francesi [Online], 184 (LXII | I) | 2018, online dal 03 juillet 2018, consultato il 18 novembre 2021. URL: http://journals.openedition.org/studifrancesi/11858; DOI: https://doi.org/10.4000/studifrancesi. 11858

Questo documento è stato generato automaticamente il 18 novembre 2021.

\section{(c) (i) (9)}

Studi Francesi è distribuita con Licenza Creative Commons Attribuzione - Non commerciale - Non opere derivate 4.0 Internazionale. 


\title{
YE YOUNG CHUNG, Malaise dans la morale bourgeoise: "Les Parents pauvres" de Balzac
}

\author{
Marco Stupazzoni
}

\section{NOTIZIA}

YE YOUNG CHUNG, Malaise dans la morale bourgeoise: "Les Parents pauvres" de Balzac, «Revue d'Histoire Littéraire de la France» 3, juillet-septembre 2016, pp. 677-695.

1 Anti-eroi di due tra i più intensi romanzi della Comédie humaine, Pons e Bette, «parents pauvres» ai margini di una società che li respinge a causa del loro statuto civile, economico e sociale, «symbolisent l'altérité que la culture dominante doit exclure pour se constituer» (p. 678). Vittime di un sistema borghese che impone loro i limiti e i vincoli della legge, i protagonisti eponimi delle due opere balzachiane si collocano all'interno di una dimensione di "hors-réalité" che smentisce i principî e che denuncia i limiti e le contraddizioni del modello borghese, ma che, allo stesso tempo, «produit sa propre jouissance irréductible à tous les "biens" moraux ou matériels de la société» (pp. 678-679). Da un punto di vista giuridico-economico, la società del xIX secolo fornisce a Pons e a Bette gli strumenti e le occasioni per agire all'interno di un «champ de trangression» nel quale è la morale stessa a determinare il reintegro della trasgressione nel sistema sociale. La ricerca della «véritable jouissance» individuale attraverso le forme della trasgressione nei confronti della legge implica il porsi ai margini della società stessa, al di là di ogni legge e di ogni sistema, vale a dire nel «domaine du mal, et en tant que telle expulsée ou marginalisée» (p. 695). 